\title{
MEDIASTENIN BENIGN LENF NODU HASTALIKLARI
}

\author{
Serdar ONAT \\ Dicle Üniversitesi Tıp Fakültesi, Göğüs Cerrahisi Anabilim Dalı, Diyarbakır, Türkiye \\ e-posta: onatserdar21@hotmail.com \\ doi:10.5152/tcb.2011.16
}

\section{GENEL BILGi}

Mediasten, zengin lenf nodu ve lenfatik ağına sahiptir. Mediasten içindeki farklı organlardan, boyundan ve diyafragmanın altından mediastinal lenf nodlarına yaygın lenf akımı mevcuttur. Lokalize inflamatuar hastalık sonucu veya primer lenfatik tümör, toraksın içinden, göğüs duvarından, memeden veya uzak bir organdan mediastinal lenf nodu etkilenir.

Mediastendeki lenf nodları üç ayrı grup altında toplanır (1).

1. Anterior Bölüm: Bu gruptaki lenf nodları ikiye ayrilır.

I. Sternal (anterior paryetal veya internal mamaryan) grup

II. Anterior mediastinal (prevasküler) grup

Sternal grup internal mamaryan arterin her iki tarafında bulunur ve ön abdominal, göğüs duvarını, diyafragmanın ön parçasını ve memenin iç kısmını drene ederler.

Prevasküler grup, timusun ön ve lateralinden, büyük damarların önünde uzanır. Bunlar daha çok mediastenin ön lenf nodu grubu olarak da bilinir. Prevasküler lenf nodları, perikardiyumun ön bölümünü, kalbin ön bölümünü, timusu, tiroidi ve mediastinal plevranın ön bölümünü drene ederler. Ayrıca özellikle sol akciğerin üst lobu da buraya drene olur.

2. Visceral (orta) Bölüm: Bu bölümde daha çok akciğer ve özefagusu drene eden lenf nodları bulunur (2-4). Bunun dişında daha az dikkat çeken paryetal grup lenf nodları tanımlanmıştır. Paryetal grup lenf nodları, diyafragmaya yakın perikardın çevresinde bulunur. Ayrica frenik sinirin diyafragmayı geçtiği yerde de bulunurlar.
3. Paravertebral Sulkus: Bu lenf nodları lateralde interkostal alan ile medialde kot başlarına komşu paravertebral alan arasında bulunurlar. Bu lenf nodları interkostal alan, paryetal plevra ve kolumna vertebralisi drene ederler. Tuberküloz gibi inflamatuar durumlarda veya primer lefomada tutulabilirler.

\section{MEDIASTENIN BENIGN LENF NODU HASTALIKLARI}

Mediastinal lenfadenopati en sık viseral kompartmanda karşımıza çıkar. En sık sağ alt paratrakeal, subkarinal ve aortopulmoner pencerede görülür. Anterior ve posterior mediastende daha az sıklıkta karşımıza çıkar. Mediastinal benign lenf nodları Tablo 1'de özetlenmişir.

\section{Mediastinal Granulomatoz Hastalıklar}

Benign mediastinal lenfadenopatinin, en sık sebebi granülomatoz hastalıklardır. Dines ve arkadaşlarına göre mediastinal granülomu olan hastaların \%40'। asemptomatiktir (5). loachim granülomların, çözünmez partiküllerin immun cevabına bağlı oluştuğunu iddia etmiştir (6). Genelde granülomlar nekroze, nekroze olmayan veya yabancı cisim olarak sınıflandırılır. Radyolojik olarak granülomlar solid lezyon olarak görülür. Yarısı kalsifiye ve bazen nekroz görülebilir. Biyopsi sonrası granülomatoz bir hastalıktan şüphe duyulduğunda alınan doku parçası mikobakteriyel ve mantar kültürüne gönderilmelidir.

Lenfadenopati, eksojen veya endojen bir ajana karşı lenf nodunun verdiği cevap sonrası oluşur. Mikroorganizmalar, otoimmün hastalıklar, immünyetmezlikler, yabancı cisimler ve tümörler olası sebeplerdir. 
loachim hiçbir mikroorganizmanın tespit edilemediği vakalarda "lenfadenopati", mikroorganizmanın sebep olduğu vakalarda "lenfadenit" teriminin kullanılmasının uygun olduğunu belirtmiştir (6).

\section{Tüberküloz}

Tuberküloz yüzyıllar boyunca en ağır hastalık olarak varlığını sürdürmüş, gelişmiş ülkelerde görülme sıklığı azalmasına rağmen, gelişmekte olan ülkelerde, ciddi sağlık problemi olarak varlığını sürdürmeye devam etmektedir. Enfeksiyon hastalıkları içinde en sık ölüm nedeni olmaya devam etmektedir (7). Dünya Sağlık Örgütü her yıl 12 milyon yeni vaka ve 3 milyon ölüm beklemektedir (8). Özellikle yaygın ilaç bağımlıı̆̆ı ve AIDS tuberkülozun fazla görülmesine katkı sağlamaktadır. HIV virusu ile M. Tuberküloz arasındaki güçlü etkileşim, multidrug direnç gelişimine ve tüberkülozun kontrolünü zor hale getirmiştir. Tüberküloz AIDS'li yedi hastadan birinin ölümüne sebep vermekte ve tüm dünyada artan tüberküloz vakalarının 1/3 ü HIV epidemisine bağlanmıştır (9). Az gelişmiş ve gelişmekte olan ülkelerde, sosyoekonomik şartlardaki kötüleşme, savaş ve göçler kontrolü daha zor hale getirmiştir.

Solunum yoluyla alınan basil daha çok alt loblara gider, makrofajlar tarafından öldürülen basillerin bir kısmı makrofaj içinde çoğalır ve alveollara yayııır. Bu bölgeye yeni gelen makrofajlar basillerin etrafını sararak ilk granülomların oluşmasını sağlarlar. Bu sırada basil yüklü makrofajlar bölgesel lenf nodlarına, özellikle hiler ve mediastinal, ulaşabilir ve hematojen yolla yayılabilirler. Giderek konakçıda gelişen aşırı duyarlıık, granülomların merkezinde kazeifikasyon nekrozuna yol açar. Primer tüberkulozda genellikle akciğer periferinde primer bir odak (Ghon odağı) ve aynı taraf hiler veya mediastinal lenfadenopati görülür. Sekonder tuberküloz daha önce duyarlı birinde primer kompleksin reaktivasyonu veya dişardan yeni ajanın alınmasıyla oluşur. Bu durumda drene eden lenf nodları tutulur. Lenfadenopati daha çok tek taraflıdır.

Özellikle çocuklarda ve primer tüberkülozun karakteri olmasına rağmen erişkinlerde de görülüp tanı problemlerine yol açmaktadır (10). Trakeobronşiyal lenf nodları, büyük boyuta ulaşıp yakın komşulukla abse, disfaji, özofagus perforasyonu, vokal kord paralizisine ve divertiküle neden olabilirler (11).

Luo ve ark. inceledikleri hastaların \%81'inde mediastinal lenfadenopatiye rağmen parankimal lezyon tespit etmemişlerdir (12).

Patolojik olarak lenf nodu dört evreden geçer (13). Evre 1; granülom oluşur. Evre 2'de kazeifikasyon nekrozu oluşur. Evre 3’te yapışıklık olmadan peri- adenit oluşur, Evre 4'te lenf nodu destruksiyonu ve yapışıklıklar oluşur.

Bilgisayarlı tomografide oval veya yuvarlak, birden fazla bölgeyi tutabilen düzgün sınırlı, unilateral hiler, ortası düşük yoğunluklu kazeifiye nekrozlu olan lenf nodleri olarak görülürler (Resim 1) (12, 13). Yüzaltı hastalık tbc lenfadenitli hastaların \%38'inde anormal akciğer grafisi tespit edilmiştir (14).

Tanı alınan biyopsiden histolojik ve mikrobiyolojik inceleme ile konur. Tanı ince iğne aspirasyon biyopsisi ile veya mediastinoskopi ile konabildiği gibi, son yıllarda kullanımı artan EBUS (endobronşiyal ultrasonografi), EUS (özafagiyal ultrasonografi) eşliğinde transbroşiyal biyopsi ile de sonuç almak mümkündür.

Tedavide antitüberküloz ilaçlar kullanılır.

\section{Fungal Enfeksiyonlar}

Günümüzde Amerika'da yetişkinlerde mediastinal granulomun en sık sebebi fungal enfeksiyonlardır. En sık sebepler sırayla Histoplasma capsulatum, Coccidiodes

Tablo 1. Benign Mediastinal Lenfadenopati Sebepleri

1. Mediastinal Granülomatöz Hastalıklar

Tüberküloz

Fungal Enfeksiyonlar

Sarkoidoz

Silikozis

Wegener Granülmatozisi

2. Castleman Hastalığı

3. Diğerleri,

Sistemik Lupus Eritemazosis

Infeksiyöz Mononukleozis

Reaktif Lenf Nodu Hiperplazisi

Amyloidozis

HIV-Pnömocytis Carini Pnömonisi

Kaynak: Machevsky MA, Kaneko M. Surgical Pathology of the Mediastinum. New York: Raven Press, 1984

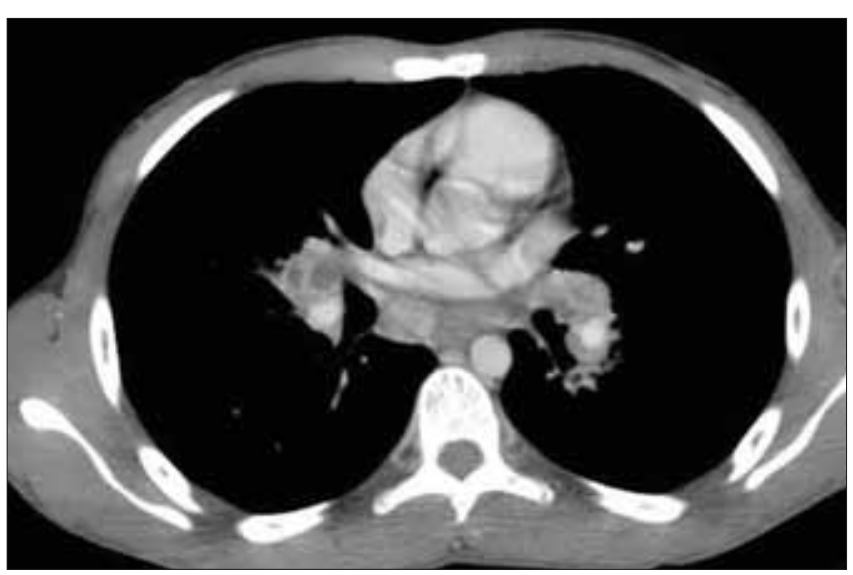

Resim 1. Tüberkülozda nekroz alanları içeren hiler lenf nodları 
immitis, Cryptococcus neoformans, ve Blastomyces dermatitidis'tir. Histoplasmin deri testine göre yapılan bir tahminde Amerikan toplumunda gizli $H$. Capsulatıum enfeksiyonu tüberküloza göre üç kat fazla bulunmuștur (15). Dines ve ark. göre, mediastinal granulomlu $H$. Capsulatıumlu hastaların \%34'ünde fibröz mediastinit geliştiğini göstermişlerdir (5). Mole ve arkadaşlarına göre Aspergillus, Mucor, Cryptococcus, Blastomyces, ve Mycobacterium enfeksiyonları sonrasıda fibröz mediastinit gelişebilir (16). Gecikmiş aşırı duyarlılık reaksiyonu sonrası oluşan yoğun inflamasyon fibröz mediastinite yol açar. Grillo, granülomun semptomatik olup olmamasına bakılmaksızın, büyük mediastinal granülomların fibröz mediastinit komplikasyonunu önlemek için, cerrahinin göze alınabileceğini belirtmiştir (17). Immün sistemi sağlam olan kişilerde Histoplasma sporları, tüberkulozdaki gibi, akciğer alt lobta subplevral, kazeifiye, kalsifiye nodül ve rejyonel hiler lenf nodunda kalsifiye alan oluştururlar (18). Konak bağışıklığı gelişince \%90 oranında kişide cilt reaksiyonu gelişir. Buna karşı tüm sistemleri tutan yoğun enfeksiyonlar AIDS gibi immunyetmezliği olan hastalarda görülür. Lenf nodları ve immun sistemin diğer komponentleri genelde yerleşim alanlarıdır. CD4+ T sayıları ağır histoplasmosis disseminasyonu sırasında ciddi düşüş gösterir (19). Yokluklarında makrofajlar mayalarca kapanır ve birçok organa taşınır. Histoplasma mayaları iyileşen granulomlarda gizli kalır ve immun yetmezlik durumunda yıllar sonra reaktive olabilir (20). \%90 civarında enfekte hasta asemptomatiktir (20). Retikülüendotelyal sistem etkilendiğinden dolayı, kemik iliği, lenf nodu, dalak ve karaciğer en sık tutulan alanlardır (21). Tanı histopatolojik inceleme ile konur. Komplemen fiksasyon ve immundiffuzyon gibi serolojik testler tanıda kullanılabilir. Kontrastı toraks CT'de kalsifikasyonlar tespit edilir. Doku tanısı için mediastinoskopi tercih edilmesi gereken araç olmasına rağmen, kanama riskini göz önüne almak gerekir. Antifungal ajanların akut enfeksiyon dışında etkinlikleri sınırıdır.

\section{Sarkoidozis}

Mediastinal ve hiler lenfadenopati yapan kanser dışı en sık sebepler arasındadır. Nedeni bilinmeyen, birçok sistemi tutabilen, dünyanın her yerinde ve her ırkında görülebilen granülomatöz bir hastalıktır (7). En sık 20-40 yaş arası erişkinler etkilenir. Sistemik bir hastalık olmasına rağmen en sık akciğerler ve intratorasik lenf nodlarını tutar. Kadınlarda erkeklerden iki kat daha fazla görülür. ABD'deki Afrika kökenliler, İsveç ve Danimarka en yüksek prevalansın bulunduğu toplumlardır. Toraks Derneği Klinik Sorunlar Çalışma Grubu 2007 yılında, iki yıllık bir çalışma sonrası, Türkiye'de insidansın 100.000'de 4 olarak tespit etmiştir.

Organik ve inorganik birçok neden ve genetik predisposan faktörler olarak suçlanmıştır, akciğerler ve lenf nodları dışında deri, göz, kalp, nörolojik sistem ve böbrek tutulumu yapabilir. Kalp tutulumu en sık ölüm nedenidir. Anjiotensin konverting enzim (ACE) seviyesi yüksek olabilir. Hiperkalsiüriye rastlanır. Akciğer ve mediasten tutulumuna göre evrelendirilir (22).

Evre 1: Bilateral hiler lenfadenopati

Evre 2: Bilateral hiler lenfadenopati ve parankimal infiltrasyon

Evre 3: Sadece parankimal infiltratlar

Kırk yaşın üzerinde görülmesi, semptomların altı aydan fazla sürmesi, dalak tutulumu, üçten fazla sistemin tutulması ve evre 3 prognozu kötüleştirir.

Tanıda cilt ve transbronşiyal biyopsiler kullanıldığı gibi tanı konulamayanlarda mediastinal lenf nodlarınden biyopsi alınabilir. Bilateral hiler lenfadenopati yaklaşık vakaların \%77'inde saptanır (23). Lenf nodları spontan olarak ortadan kalkabilir, İsveç toplumundan sarkoidoz nedeniyle incelenen hastalarda mediastinal lenf nodlarının \%85'inin kaybolduğu belirtilmiştir (7).

Kazeifikasyon nekrozu göstermeyen granülom, sarkoidozun karakteristik histopatolojisini yansıtır. Granülomlar epiteloid hücreler, dev hücreler ve lenfositler, plasma hücreleri ve fibroblastlar içerir (7). Her ne kadar nekroz olağan değilse de bazen, fokal fibroblastik nekroz görülebilir ve bunun görülmesi sarkoidoz tanısını dışlamaz. Yaygın bir nekroz görülmez. Sarkoid granülomlarında periferden başlayıp merkeze ilerleyen tam fibrozis veya hyalinizasyonla sonuçlanan fibrotik değişiklikler gelişebilir. Granülomlar kaybolabilir veya fibrozise ilerleyebilir. Sarkoidozda granülomlar birbirine yakın ve keskin sınırla ayrımaları ve nekroz bulundurmamasıyla diğer granülomlardan ayrılırlar. Kalsifikasyon içermeyen ve özellikle bilateral hiler lenfadenopatiler sarkoidoz tanısını akla getirmeli ve ek klinik belirtiler ile değerlendirme yapılmalıdır. Sarkoidozda karakteristik olarak bilateral, simetrik hiler ve sağ paratrakeal lenfadenopati (Resim 2) görülür.

\section{Silikozis}

Silikozis, serbest silika kristallerinin inhalasyonu ile oluşan ve tedavisi olmayan bir akciğer hastalığıdır (24). Kısa bir latent zamanı ve hızlı bir progresyona sahiptir. En eski meslek hastalıklarından birisi olup tüm dünyada yılda binlerce ölüme sebebiyet vermektedir. İki klinik formu vardır, silikoproteinozis denen; akut formu ve klasik veya kronik formu. Akut formu son yıllarda Türkiye'de de artan kot taşlamacılığı (kumlamacılığı) sonrası oluşur (25). Bunun dışında 


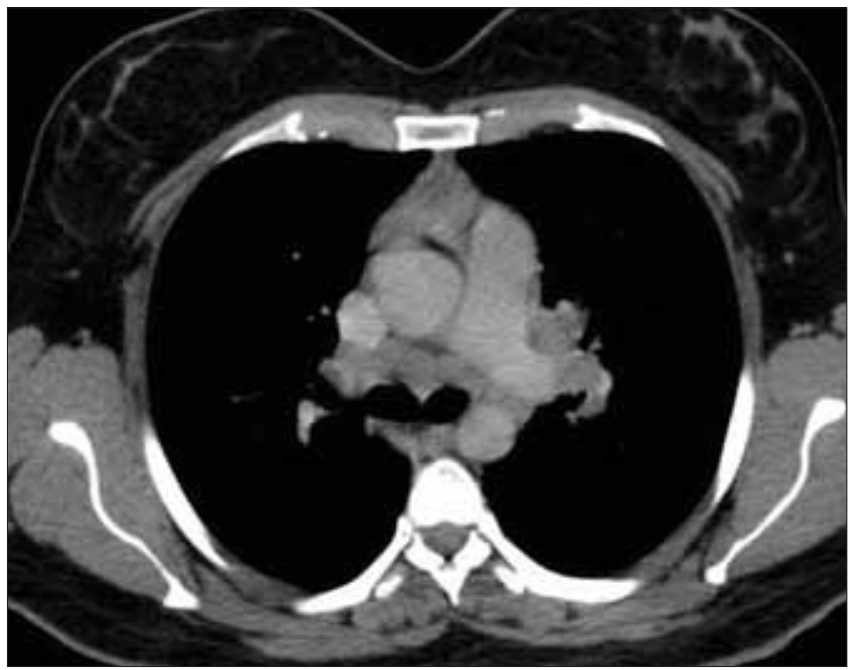

Resim 2. Sarkoidozda görülen bilateral hiler lenf nodları

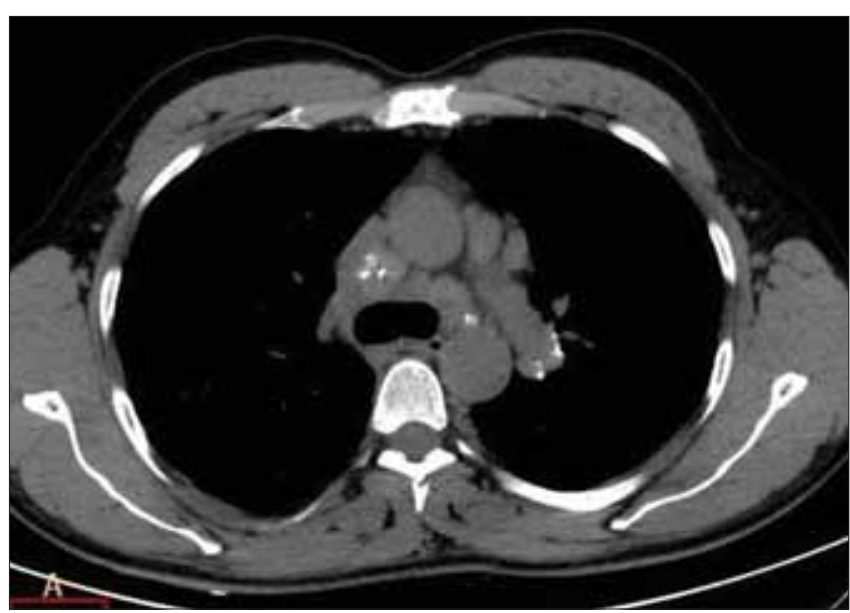

Resim 3. Silikoziste kalsifiye lenf nodları

maden ve tünel işçilerinde de akut silikozis görülür. Kronik formu maruziyet ortadan kalksa bile yıllar sonra görülebilir ve yaygın parankimal nodüllerle karşımıza çıkar (26). Silikoziste parankimal nodüller ve plevral kalınlaşmanın yanısıra mediastinal lenfadenopatilere sebep olur. Kronik silikoziste lenfadenopati \%63.5 oranında saptanırken akut durumlarda bu oran \%45.5 olarak bulunmuştur $(27,28)$. Lenfadenopatilerde kalsifikasyon görülmesi nadirdir (Resim 3). Bazen hiler lenfadenopatilerde görülen yumurta kabuğu şeklindeki kalsifikasyon interstisyel fibrozisin öncüsü olabilir. Hiler lenf nodlarında kavitasyon ilerlemiş hastalık durumunda veya mikobakteriyel bir süperenfeksiyon sonrası görülebilir.

\section{Wegener Granülomatozisi}

Alt ve üst solunum yollarında nekrotizan anjiitis ve fokal glomerülnefritle karakterli bu granülamatöz hastalıkta, mediastinal tutulum, nadir de olsa, görülebilir. George Wegenerli hastaların sadece \%2'sinde bu patolojiye bağlı mediastinal lenfadenopati tespit etmiş olup, lenfadenopati saptanan Wegenerli hastalarda diğer sebeplerin ekarte edilmesi gerektiğini önermiştir (29). Histopatolojik incelemede nekroz ve vaskulit tespit edilir.

\section{Castleman Hastalığı}

Mediastinal lenf nodunun büyümesiyle karakterli olan hastalık, lenf nodu hamartomu, anjiofolikuler lenf nodu hiperplazisi, benign dev lenfoma, dev lenf nodu hiperplazisi ve folikuler lenforetikuleroma gibi adlarla anılmıştır (30). Genellikle asemptomaktir. Genelde yaş ve ırk ilişkisi olmamasına rağmen hastaların çoğuna 30 yaşından önce tanı konur. Etyolojik neden tam olarak bilinmemektedir. Suçlanan etyolojik ajanlardan Kaposi sarkom virusu olarak bilinen HHV-8 virusu vakaların \%5-25'inde saptanmıştır (31). Lokalize ve multisentrik olmak üzere iki formu vardır. IL-6 seviyesi multisentrik formunda yüksek bulunmuştur (32). Castleman hastalığına eşlik eden bazı patolojiler şu şekilde sıralanabilir; bazı hematolojik bozukluklar (refrakter anemi, otoimmun sitopeni, trombositik trombositopenik purpura, miyelofibrozis, lupus), dermatolojik patolojiler (pemfigus vulgaris, kaposi sarkomu), pulmoner patolojiler (plevral efüzyon, bronşiolitis obliterans), böbrek bozuklukları (böbrek yetmezliği, nefrotik sendrom), nörolojik bozukluklar (periferik nöropati, miyastenia gravis), lenfoma, amyliodozis ve perikardiyal efüzyon. Lokalize formu vasküler hyalin (HV-CD) ve plazma hücre (PC) formu diye ikiye ayrilır. HV-CD formu unisentrik vakaların \%80'ını kapsar (33). Hyalin vasküler tipi lenf nodunu da tutan büyük mediastinal kitle şeklinde karşımıza çıkar. Semptomlar genelde basıya bağlıdır; nefes darlığı veya damarsal basıya bağlı olarak özofagus varisleri görülebilir $(34,35)$. Tanı genellikle tesadüfen çekilen akciğer grafisinde mediasten genişlemesiyle konur. Mediasten lokal tutulumun en sık olduğu yerdir. Mediasten dışındaki lenf nodları ve lenf nodu olmayan dokularda da rastlanabilir. Histolojik olarak hyalin- vasküler ve plasma hücreleri saptanır. Radyolojik olarak düzgün sınırı lobüle mediasten kitlesi şeklinde karşımıza çıkar. Lokalize formu için cerrahi önerilmekte ve inkomplet cerrahi veya cerrahiye uygun olmayanlarda radyoterapi önerilmiştir $(34,36)$. Plazma hücreli formu lokalize formun \%10-20'si kadardır. Geniş bir yaş grubunda görülmekle beraber, genelde vaskülerhyalin formundan daha geç yaşlarda görülür. Sistemik semptomlara yol açabilir. Cinsiyet ayrımı yoktur (34). Hyalin vasküler gruba göre plazma hücreli castleman mediasteni daha az tutar. Cerrahi tek başına yeterli olmadığından kemoterapi eklenmelidir (37). Multisentik formu için kemoterapi ve/veya radyoterapi önerilme- 
ktedir. Prognoz için intiyatlı davranmak gerekir. Takip eden bir malignensi için yakın takip önerilmektedir. Vasküler hyalin formunda lenfomaya eğilim saptanmazken plazma hücreli formunda lenfoma birlikteliği daha fazladır (6).

\section{Diğer sebepler}

Amioloidoz, kalp yetmezliği ve sistemik skleroz gibi birçok neden mediasten lenf nodu tutulumu yapabilir (38).

\section{KAYNAKLAR}

1. Shields TW. Lymphatics of the lungs.In Shields TW, LoCicero J, Reed Carolyn E, Feins RH.ed General Thoracic Surgery vol 1, 7th.ed.Philadelphia: Lippincott Williams and Wilkins; 2009: 87-101.

2. Naruke T, Suemasu K, Ishikawa S. Lymph node mapping and curability at various levels of metastasis in resected lung cancer. J Thorac Cardiovasc Surg 1978;76:832-9.

3. Rusch VW, Asamura H, Watanabe H, Giroux DJ, RamiPorta R, Goldstraw P; Members of IASLC Staging Committee. The IASLC lung cancer staging project: a proposal for a new international lymph node map in the forthcoming seventh edition of the TNM classification for lung cancer. J Thorac Oncol. 2009;4:568-77.

4. American Joint Committee on Cancer (AJCC), Chicago, Illinois. Cancer Staging Manual, Seventh Edition New York Springer, ,2010.

5. Dines DR, Bernatz PE, Pairolero PC. Mediastinal granuloma and fibrosing mediastinitis. Chest 1979;75:320324.

6. Harry L. Ioachim, L. Jeffrey Medeiros .loachim's Lymph Node Pathology, 4th edition 2008. Lippincott Williams \& Wilkins.

7. Bloom BR, Murray CJL. Tuberculosis: commentary on a reemergent killer. Science 1992;257:1055-64.

8. Global tuberculosis programme. In global tuberculosis control. WHO report 1998. Geneva: World Health Organization, 1998;237.

9. Sepkowitz KA. One disease two epidemics. AIDS at 25. N Engl J Med 2006;354:23.

10. Kessel MM, Agkatsev TV, Lazareva laV, Perelman MI. Surgical treatment for tuberculosis of intrathoracic lymph nodes in children and adolescents. Probl Tuberk Bolezn Legk 2006; 5: 33-35.

11. Wilkins EW Jr, Galdabini JJ. Esophageal diverticulum associated with a mass in the neck. $\mathrm{N}$ Engl $\mathrm{J}$ Med 1977;296:384-90.

12. Luo MY, Liu L, Lai LS, et al. Deepgoing study on intrathoracic tuberculous lymphadenitis in adults using multidetector CT. Chin Med J (Engl). 2010;123:1283-8.

13. Moon WK, Im JG, Yeon KM, Han MC. Mediastinal tuberculous lymphadenitis: CT findings of active and inactive disease. AJR Am J Roentgenol 1998;170:715-8.

14. Polesky A, Grove W, Bhatia G. Peripheral tuberculous lymphadenitis: epidemiology, diagnosis, treatment, and outcome. Medicine 2005;84:350-62.
15. Edwards LB, Acquaviva FA, Livesay VT, et al. An atlas of sensitivity to tuberculin, PPD-B and histoplasmin in the United States. Am Rev Respir Dis 1969;99:1-132.

16. Mole TM, Glover J, Sheppard MN. Sclerosing mediastinitis: a report on 18 cases. Thorax 1995;50:280-3.

17. Mathisen DJ, Grillo HC. Clinical manifestation of mediastinal fibrosis and histoplasmosis. Ann Thorac Surg 1992;54:1053-8.

18. Reynolds RJ 3rd, Penn RL, Grafton WD, George RB. Tissue morphology of Histoplasma capsulatum in acute histoplasmosis. Am Rev Respir Dis 1984;130:317-20.

19. Hajjeh RA. Disseminated histoplasmosis in persons infected with human immunodeficiency virus. Clin Infect Dis 1995;21:108-10.

20. Chang RC. Histoplasmosis. eMedicine updated Sept. 2005.

21. Levitz SM, Mark EJ. Case 38-1998. A 19-year old man with the acquired immunodeficiency syndrome and persistent fever. N Engl J Med 1998;339:1835-43.

22. Consensus Conference: activity of sarcoidosis. Eur Respir J 1994;7:624-7.

23. Winterbauer $\mathrm{RH}$, Belic $\mathrm{N}$, Moores $\mathrm{KD}$, et al. A clinical interpretation of bilateral hilar adenopathy. Ann Intern Med 1973;78:65-71.

24. World Health Organisation: [http://www.who.int/ mediacentre/factsheets/fs238/en/] webcite WHO.

25. Cimrin A, Sigsgaard T, Nemery B. Sandblasting jeans kills young people. Eur Respir J 2006;28:885-6.

26. Chong S, Lee KS, Chung MJ, et al: Pneumoconiosis: Comparison of Imaging and Pathologic Findings. RadioGraphics 2006;26:59-77.

27. Lopes AJ, Mogami R, Capone D, et al. High-resolution computed tomography in silicosis: correlation with chest radiography and pulmonary function tests. J Bras Pneumol 2008;34:264-72.

28. Ozmen CA, Nazaroglu $\mathrm{H}$, Yildiz $\mathrm{T}$, et al. MDCT findings of denim-sandblasting-induced silicosis: a cross-sectional study. Environ Health. 2010;17:9-17.

29. George TM. Mediastinal mass and hilar adenopathy: rare thoracic manifestations of Wegener's granulomatosis. Arthritis Rheum 1997;40:1992-7.

30. Castleman B, Iverson L, Menendez VP. Localized mediastinal lymph-node hyperplasia resembling thymoma. Cancer 1956;9:822-30.

31. Simpson GR, Schulz TF, Whitby D, et al. Prevalence of Kaposi's sarcoma associated herpesvirus infection measured by antibodies to recombinant capsid protein and latent immunofluorescence antigen. Lancet 1996;348:1133-8.

32. Oksenhendler E, Carcelain G, Aoki Y, et al. High levels of human herpesvirus 8 viral load, human interleukin-6, interleukin-10, and $C$ reactive protein correlate with exacerbation of multicentric Castleman disease in HIVinfected patients. Blood 2000;96:2069-73.

33. Casper C. The aetiology and management of Castleman disease at 50 years: translating pathophysiology to patient care. Br J Haematol 2005;129:3-17.

34. Keller AR, Hochholzer L, Castleman B. Hyaline-vascular and plasma-cell types of giant lymph node hyperplasia of the mediastinum and other locations. Cancer 1972;29:670-83. 
35. Serin E, Ozer B, Gumurdulu Y, et al. A case of Castleman's disease with "downhill" varices in the absence of superior vena cava obstruction. Endoscopy 2002;34:160-2.

36. Chronowski GM, Ha CS, Wilder RB, et al. Treatment of unicentric and multicentric Castleman disease and the role of radiotherapy. Cancer 2001;92:670-6.

37. Menke DM, Camoriano JK, Banks PM. Angiofollicular lymph node hyperplasia. A comparison of unicentric, multicentric, hyaline vascular, and plasma cell types of disease by morphometric and clinical analysis. Mod Pathol 1992;5:525-30.

38. Olak J. Benign lymph node disease involving the mediastinum. In Shields TW, LoCicero J, Reed Carolyn E, Feins RH.ed General Thoracic Surgery vol 2, 7th.ed.Philadelphia: Lippincott Williams and Wilkins; 2009;2363-8. 